\title{
De historische dimensie van taalbondverschijnselen
}

\section{The Historical Dimension of Sprachbund Phenomena}

\author{
Martin Konvička
}

\begin{abstract}
Sprachbund phenomena can be identified as such if the following three conditions are met. First, the languages in question are in direct contact with each other. Second, the languages are typologically distinct from the neighbouring languages. Third, it is clear that these distinct typological features are innovations resulting from contact with the other languages at hand. Finding an answer to the last question requires insights from historical linguistics. However, using the example of Standard Average European, I argue that the historical dimension is too often neglected and non-linguistic factors are favoured instead.
\end{abstract}

\section{Keywords}

linguistic areas; Standard Average European; Sprachbund; language contact; historical linguistics; contact-induced change; areal features 


\section{Inleiding}

Taalbondonderzoek verenigt in zich een reeks van taalwetenschappelijke subdisciplines. Voorbeelden hiervan zijn typologisch onderzoek naar verschillende talen, het onderzoek naar taalcontactsituaties en ten slotte ook historische taalwetenschap. In het kader van het taalbondonderzoek concentreert men zich op regio's waar meerdere talen met elkaar in contact komen. Door dergelijk taalcontact kunnen in de betrokken talen structurele innovaties ontstaan die de taalbondleden van de buurtalen onderscheiden. Helaas wordt taalbondonderzoek regelmatig tot puur typologisch onderzoek gereduceerd. In dat geval ontbreekt de historische dimensie van het onderzoek. Echter, alleen als een potentiële taalbond vanuit een historisch perspectief bestudeerd wordt, kan vastgesteld worden of de onderzochte innovaties inderdaad producten van het taalcontact en dus taalbondverschijnselen zijn.

De rol van de historische dimensie wordt in het taalbondonderzoek vaak onderschat. De consequenties worden in het huidige artikel besproken. Deze gevolgen worden belicht op basis van verschillende pogingen om Europa als een taalbond te bestuderen. De discussie over Standard Average European (SAE) zal hierbij een centrale rol spelen. In dit artikel probeer ik aan te tonen dat verklaringen vaak vanuit culturele en ideologische perspectieven worden aangevoerd en niet op basis van de historische dimensie die in het kader van een linguïstisch taalbondonderzoek primair zou moeten zijn.

\section{Geschiedenis Europees taalbondonderzoek}

Degene die voor de eerste keer Albanees, Bulgaars, Grieks en Roemeens als verschillende talen met verrassend sterk convergerende grammatica's beschreef, was Jernej KOPITAR (1826). Franz MIKLOSICH (1861: 5) was echter pas de persoon die probeerde deze gemeenschappelijke trekken door taalcontact te verklaren, namelijk via de invloed van een onbekend en al lang niet meer aanwezig substraat. Hoewel zijn verklaring later als onhoudbaar afgewezen werd (vgl. KLAGSTAD 1963), combineert zijn aanpak alle voor het taalbondonderzoek relevante aspecten. Hij toonde aan dat de talen op de Balkan typologisch bijzondere kenmerken bezitten die in de buurtalen ontbreken. Verder argumenteerde hij dat de Balkanismen geen gevolg zijn van een gemeenschappelijke oorsprong van de onderzochte talen. Hij pleitte er daarentegen voor dat de Balkanismen een gevolg van taalcontact moesten zijn.

Alleen het woord taalbond gebruikt Miklosich nog niet. Deze term heeft Nikolaj TROEBETSKOJ (1928: 18) geïntroduceerd voor groepen talen die weliswaar gemeenschappelijke trekken vertonen, maar niet genetisch verwant zijn. In vergelijking met Miklosich speelde voor Troebetskoj de typologische kijk een belangrijkere rol. Pas Roman JAKOBSON (1931a [1962], 1931b [1962]) gebruikte de term taalbond in de moderne betekenis, namelijk voor groeperingen talen met gemeenschappelijke trekken die niet genetisch met elkaar verwant zijn en die bovendien met elkaar in con- 
tact staan. ${ }^{1}$ Jakobsons werk kenmerkt daarom het begin van het moderne taalbondonderzoek.

Indien meerdere talen gemeenschappelijke trekken delen, zijn in beginsel de volgende vier verklaringen denkbaar: een typologisch toeval, resultaat van natuurlijke processen, ${ }^{2}$ resultaat van genetische verwantschap en resultaat van taalcontact (LIST 2014: 55-56). De taak van de taalbondonderzoekers is vooral de twee laatstgenoemde factoren te onderscheiden. Taalbondverschijnselen kunnen alleen als zodanig gelden als zij op taalcontact teruggevoerd kunnen worden. Noodzakelijkerwijs moet met behulp van de historische taalwetenschap vastgesteld worden of de onderzochte kenmerken geen resultaat van autochtone taalverandering zijn. Dat wordt echter niet altijd gedaan, omdat culturele of typologische verklaringen gebruikt worden. Dit wordt in de volgende passages aangetoond.

\section{De culturele dimensie van taalbonden}

Voorbeelden van hoe niet-linguïstische aspecten het taalbondonderzoek beïnvloeden, zijn Troebetskojs en Jakobsons werken over de Euraziatische taalbond. In hun taalbondonderzoek heeft de culturele en politieke invloed van het Eurazianisme de overhand.

De Euraziatische ideologie begon zich kort na de Eerste Wereldoorlog te vormen, in de tijd toen de communisten in Rusland aan de macht kwamen. Het Eurazianisme bekritiseerde de superioriteit van de Europese cultuur en verdedigde het recht van de Russische maatschappij op een zelfstandige culturele identiteit. Volgens de Eurazianisten, zoals Lev Goemilov $(* 1912+1992)$, is Rusland een specifieke culturele eenheid en niet een bestanddeel van Europa of van Azië. Zich baserend op allerlei archeologische, geografische, historische en antropologische argumenten, pleitten ook JAKOBSON (1931a [1962: 138]) en TROEBETSKOJ (1920) voor een Euraziatische identiteit van de Russische wereld.

De Euraziatische trekken zouden onder andere ook in het Russisch en de buurtalen merkbaar moeten zijn. Bijvoorbeeld in de fonologische systemen van deze talen, die met elkaar convergeren (vgl. JAKOBSON 1931a [1962]). Hoewel vaststaat dat Jakobson en Troebetskoj wezenlijk hebben bijgedragen aan de ontwikkeling van

1 Taalcontact is essentieel om te kunnen bepalen of een gezamenlijke trek een typologisch toeval of inderdaad een taalbondverschijnsel is. Voor een typologische vergelijking speelt de oorsprong van een structuur geen rol, terwijl de gedeelde kenmerken van een taalbond door taalcontact gemotiveerd moeten zijn. Als daarom twee talen gemeenschappelijke structurele trekken, maar geen gemeenschappelijke geografische grenzen delen, is het onwaarschijnlijk dat zij leden van een taalbond zijn (vgl. MASICA 2001: 208-209). Typologische overeenkomsten tussen meerdere talen zijn dus niet genoeg om een taalbond te rechtvaardigen. Zo bezitten de Afrikaanse talen Hausa en Wolof evenals het Nederlands bepaalde en onbepaalde lidwoorden. Dit feit is echter alleen een typologische observatie. Van een taalbond tussen het Nederlands, Hausa en Wolof kan geen sprake zijn, omdat deze talen niet in contact met elkaar komen.

2 Bedoeld worden overeenkomsten die het gevolg zijn van de ontwikkeling van spraakorganen en van algemene denotatiepraktijken die universeel voor de menselijke taal zijn. Een voorbeeld hiervan is het woord mama in verschillende talen. 
het taalbondonderzoek, moet de vraag worden gesteld of zij inderdaad enkel een taalwetenschappelijk onderzoek beoogden. POTTELBERGE (2001: 7) noteert dat Jakobson en Troebetskoj niet van onwetenschappelijkheid beticht kunnen worden, maar tegelijkertijd stonden in hun werk naast de taalwetenschappelijke motivatie ook ideologische redenen op de voorgrond (vgl. FRIEDMAN 2012: 114, BIRNBAUM 1965: 16).

Een ander voorbeeld is te vinden bij BECKER (1948). In zijn werk benadrukte hij de invloed van cultuur, geschiedenis en gemeenschappelijke maatschappelijke ontwikkelingen op de Europese talen. De verklaring voor de convergentie tussen de Europese talen zoekt hij echter niet in het taalcontact, maar eerder in de rol van de hoge cultuur. Onder hoge cultuur verstaat hij (BECKER 1948: 15) de invloed van gestandaardiseerde schrijftalen, hogere maatschappelijke lagen en politieke centra. Becker deelde de leden van een taalbond in Meistersprachen en Schülersprachen op. De Meistersprachen fungeren in zijn model als de bronnen van veranderingen en de Schülersprachen nemen deze veranderingen passief over. Afhankelijk van de mate waarin de Schülersprachen door de Meistersprachen beïnvloed zijn, verdeelde hij ze nog verder in volledige en in perifere leden.

Ernst LEWY (1964) presenteerde een soortgelijk, sterk op culturele, niet-linguïstische aspecten georiënteerde aanpak. Hij deelde de Europese talen in twee hoofdgroepen op: de Atlantische (Engels en West-Romaans) en de Oostelijke (West- en Oost-Slavisch) talen. Naast deze twee grote groeperingen onderscheidt hij ook nog de volgende drie kleinere groepen in Europa: het Centrale Gebied (Duits en Hongaars), het Arctische Gebied (in het Noorden van het Oostelijke Gebied) en het Balkangebied (Albaans, Grieks, Roemeens en alle Zuid-Slavische talen).

Deels is LEWY's (1964: 100-108) argumentatie inderdaad linguïstisch. Zo motiveert hij de Oostelijke groep door het conservatieve talige karakter van de Slavische talen te vergelijken met de talen in de Atlantische groep. Tegelijkertijd gebruikt Lewy onder andere ook de verspreiding van moderne techniek, zoals auto's en radio's, in verschillende maatschappijen in zijn argumentatie om zijn ,taalbonden' te rechtvaardigen.

In dezelfde niet-taalwetenschappelijke geest probeert ook Gyula DÉCSY (1973) de Europese talen te categoriseren en hij stelt daarvoor tien separate taalbonden voor. Linguïstisch relevant zijn deze groeperingen echter niet. Zijn litorale taalbond (DÉCSY 1973: 60) bestaat bijvoorbeeld uit het Fries, Nederlands, Baskisch, Spaans, Portugees en Maltees. De motivatie om deze talen tot één groep samen te voegen, is voor Décsy de maritieme invloed op de talen. Taalcontact als factor wordt nauwelijks genoemd.

Vergelijkbare factoren zouden ook de eilandtalen en de diaspora-talen (DÉCSY 1973: 138-152) verbinden. De groep van eilandtalen bevat Luxemburgs, Reto-Romaans, Sorbisch en Gagaoezisch. Hun enige gemeenschappelijk kenmerk is het feit dat zij door Décsy tot geen van de andere taalbonden gerekend werden. De diaspora-talen representeren verschillende talen die door in diaspora levende bevolkingen gebruikt worden. In grammaticaal opzicht delen beide groepen echter niet veel, hoe- 
wel de linguïstische aspecten in het taalbondonderzoek eigenlijk centraal moeten staan.

In vergelijking met de bovengenoemde, eerdere pogingen om Europese taalbonden te bestuderen, is het onderzoek naar de vermoedelijke pan-Europese taalbond, bekend onder de naam Standard Average European, linguïstisch uitvoerig onderbouwd. Echter ook hier wordt de historische dimensie niet grondig genoeg bestudeerd, zoals uit de volgende beschouwing zal blijken.

\title{
4. Standard Average European
}

Voordat de theoretische vragen van het moderne onderzoek naar Standard Average European bediscussieerd kunnen worden, wordt allereerst kort op de ideële geschiedenis van het begrip ingegaan. De geschiedenis van Standard Average European begint bij Benjamin Lee Whorf. Hij gebruikte de term als een praktische afkorting tijdens zijn studies van de Hopi-taal om de grootste verschillen tussen de Noord-Amerikaanse taal en de Indo-Europese talen duidelijk te maken. De term zelf, zoals AUWERA (2009: 176) opmerkt, was voor Whorf niet zeer belangrijk. In dezelfde betekenis heeft Whorf afwisselend ook General Indo-European gehanteerd. De achtergrond van zijn term beschrijft WHORF (1941: 77-78) zelf op de volgende manier:

\begin{abstract}
"The work began to assume the character of a comparison between Hopi and western European languages. It also became evident that even the grammar of Hopi bore a relation to Hopi culture, and the grammar of European tongues to our own "Western" or "European" culture. And it appeared that the interrelation brought in those large subsummations of experience by language, such as our own terms 'time,' 'space,' 'substance,' and 'matter.' Since, with respect to the traits compared, there is little difference between English, French, German, or other European languages with the POSSIBLE (but doubtful) exception of Balto-Slavic and non-Indo-European, I have lumped these languages into one group called SAE, or "Standard Average European."”
\end{abstract}

Vanwege de niet consequente terminologie lijkt het begrip van Europa als talige eenheid dus geen prioriteit voor Whorf. ${ }^{3}$ Zijn term werd overigens pas later door de taalbondonderzoekers overgenomen en voor hun doel, de studie van de pan-Europese taalbond, geadapteerd.

Whorfs term wordt later door DÉCSY (1973: 29) gebruikt, die hem voor zijn taalbond van de vijf grote Europese talen, oftewel Duits, Frans, Engels, Italiaans en

3 De meeste - indien niet alle - taalwetenschappers in de Westerse linguïstiek, lijden volgens DAHL (1990: 3) onder een min of meer onbewuste vooringenomenheid door hun persoonlijke talige achtergrond: "I think most of us still have a subconscious view of the "default" language as being something between English, French, German and perhaps Italian - actually, and probably not accidentally, something very much like Esperanto." Mijns inziens is Whorfs Standard Average European of General Indo-European precies wat Dahl "default language" noemt (zie ook POTTELBERGE 2001: 11). De verbinding met het moderne taalbondonderzoek is daarom alleen terminologisch en niet inhoudelijk. 
Russisch, heeft gebruikt. Décsy's criterium om een taal bij deze groep op te nemen was dat deze door meer dan vijftig miljoen moedertaalsprekers wordt gesproken.

Een grote stap in de ontwikkeling van Standard Average European was het project EUROTYP in de jaren negentig (KÖNIG 2010). Een internationaal linguïstisch team zocht naar gemeenschappelijke typologische trekken van de Europese talen die het idee van een pan-Europese taalbond zouden ondersteunen. Volgens HASPELMATH (2001: 1493) moeten de gemeenschappelijke kenmerken aan de volgende vier criteria voldoen om als taalbondverschijnselen te kunnen gelden. Ten eerste moet de meerderheid van de Europese talen deze kenmerken bezitten. Ten tweede moeten zij in de buurtalen ontbreken. Ten derde moeten de kenmerken in de oostelijke Indo-Europese talen, namelijk Armeens, Iraans en Hindi, ontbreken. Ten vierde moeten deze kenmerken in de meerderheid van andere talen in de wereld afwezig zijn. Met andere woorden, deze kenmerken moeten de Europese talen er in vergelijking met hun omgeving exotisch uit laten zien (vgl. DAHL 1990).

Opvallend is dat onder de bovengenoemde criteria de voorwaarde ontbreekt dat de kenmerken innovaties moeten zijn om als taalbondverschijnselen te kunnen gelden. Of het in feite om innovaties gaat die de resultaten van taalcontact zijn, kan alleen door historisch taalwetenschappelijk onderzoek vastgesteld worden. Deze vraagstelling komt in dit project echter nauwelijks aan bod. Er wordt weliswaar over potentiële historische verklaringen van de Europeanismen nagedacht (HASPELMATH 2001: 1506-1507), maar deze discussie blijft te algemeen omdat een universele historische verklaring voor alle gevonden Europeanismen gezocht wordt. Meer dan een taalbondonderzoek is het hele project daarom een typologisch onderzoek. Dat bevestigt overigens ook SIEWIERSKA (1998: v-vi) in haar beschrijving van het project als een typologische vergelijking van de Europese en niet-Europese talen.

Gebaseerd op de bovengenoemde criteria stelde HASPELMATH (2001: 15031504) de volgende lijst van twaalf pan-Europese taalbondverschijnselen samen:

1) Bepaalde en onbepaalde lidwoorden een huis versus het huis

2) Bijzinnen met verbogen betrekkelijke voornaamwoorden het huis dat ik bewoon versus de man die ik zag

3) Hulpwerkwoord hebben voor de voltooid tegenwoordige tijd Jan heeft voor zijn moeder een lied gezongen.

4) Ondervindend voorwerp als experiencer $i k$ vrees versus het spijt me

5) Lijdende vorm met een participium het boek wordt geschreven

6) Wederkerende werkwoorden van niet wederkerende werkwoorden gevormd openen versus zich openen

7) Externe possessoren in de datief De supporters rukten de voetballer de kleren van het lijf.

8) Geen dubbele werkwoordelijke negatie 
het is geen auto versus * het is geen auto niet

9) Comparatief met behulp van partikels

een olifant is groter dan een muis

10) Equatieve constructies gebaseerd op betrekkelijke constructies

een olifant is niet zo groot als een muis

11) Strikte congruentiemarkeerders tussen werkwoorden en persoonlijke voornaamwoorden

zij moet de afwas doen versus * $\emptyset$ moet de afwas doen

12) Verschil tussen wederkerende en intensiverende voornaamwoorden

hij verdedigt zich versus hij verdedigt zichzelf

Soms beperkte de kritiek zich tot details van zulk een omvangrijk project (STOLZ 2006: 283-284), maar de volgende opmerkingen met betrekking tot de methodologie waren ernstiger. Enkele critici zoals KORTMANN (2009) of MURELLI - KORTMANN (2011) zien de focus op standaardtalen als een zwak punt. Guido SEILER (2010) pleit in deze context zelfs voor een onderzoek van Non-Standard Average European. De Europese standaardtalen zijn, aldus Seiler, kunstmatige producten die het reële taalgebruik en daardoor ook de reële grammaticale opbouw slechts beperkt kunnen weerspiegelen. Hij beoogt de resultaten van het project EUROTYP door een verder typologisch onderzoek van verschillende dialecten, sociolecten en andere variëteiten van de Europese talen te verbeteren. Voor een soortgelijke aanpak pleit ook AUER (2004: 69-72), die onderstreept dat de standaardtaal slechts één mogelijke realisatie van de onderzochte taal is en andere variëteiten niet buiten beschouwing hoeven te blijven.

Zoals al besproken werd, worden taalbondverschijnselen gekarakteriseerd doordat zij de resultaten van taalcontact zijn. Het is daarom niet genoeg om enkel door een typologische bril een statisch beeld van de onderzochte talen te schetsen. ${ }^{4}$ Met behulp van diachrone data moet daarnaast worden bewezen dat het inderdaad om innovaties gaat die door taalcontact zijn ontstaan.

In dit opzicht is een van grootste problemen van de twaalf bovengenoemde Europeanismen hun uitsluitend typologische karakter. Echte taalbondverschijnselen zijn echter alleen verklaarbaar vanuit een historisch perspectief. Van belang is dat de talen van een taalbond een dynamische ontwikkeling in een gemeenschappelijke richting aantonen. De resultaten van het onderzoek naar Standard Average European tonen weliswaar aan dat de Europese talen typologisch soortgelijk zijn, maar die bewijzen daarmee nog niet dat de gevonden Europeanismen taalbondverschijnselen zijn.

In een soortgelijke richting hebben HÜNING (2002: 149) en POTTELBERGE (2001: 18) de twaalf kenmerken bekritiseerd. Zij verwezen er bijvoorbeeld naar dat het Engels alsook het Nederlands niet meer over externe possessoren in de datief

4 HAMP (1977) beschrijft typologisch onderzoek als achroon en verwijst naar de afwezigheid van de factoor tijd. Taalbondonderzoek moet daarentegen in wezen diachroon zijn. Terwijl typologisch onderzoek zich met de vaststelling van gezamenlijke kenmerken bezighoudt, gaat het taalbondonderzoek een stap verder en onderzoekt ook hun ontstaan. 
(vierde kenmerk in HASPELMATH 2001) beschikt. Voorbeelden van dergelijke constructies in het Nederlands komen uitsluitend in archaïsch, metaforisch taalgebruik of in vaste uitdrukkingen zoals (13) voor. Externe possessoren in andere contexten (14) zijn daarentegen in het Nederlands niet mogelijk.

13) De supporters rukten de voetballer de kleren van het lijf.

14) *Ik heb me het been gebroken. Ik heb mijn been gebroken.

Zoals THOMASON - KAUFMAN (1988: 95) opmerken zijn "Sprachbund situations [...] notoriously messy." Ik wil in deze bijdrage beargumenteren dat voor deze chaotische situatie ten minste twee belangrijke en samenhangende redenen bestaan. Aan de ene kant is er het ontbrekende of ontoereikende historische perspectief en aan de andere kant de impliciete, maar soms ook expliciete, ideologie achter sommige taalbondprojecten. Als de diachrone kijk, die de potentiële taalbondverschijnselen als zodanig verklaart, helemaal afwezig is, blijven niet zelden alleen typologisch vastgestelde overeenkomsten over. Het zijn vaak ideologische redenen die zorgen voor de sprong van een typologische constatering naar de vaststelling van een taalbond. In tegenstelling tot typologisch onderzoek is taalbondonderzoek een historische discipline. Taalbondonderzoek probeert de gemeenschappelijke talige structuren te verklaren. Daarom moet de vraag naar de oorsprong van deze gezamenlijke trekken een centrale rol spelen, hoewel een precies antwoord op deze vraag, zoals HÜNING (2008: 50) opmerkt, meestal gecompliceerd is.

De vraag naar de oorsprong van de kenmerken van de Europese taalbond ontbreekt bij HASPELMATH (1998: 272, 2001: 1506) niet geheel. Hij somt de volgende vijf mogelijke verklaringen voor de vastgestelde convergentie op. Ten eerste is er de invloed van de proto-Indo-Europese structuren en de assimilatie van enkele niet Indo-Europese structuren. Ten tweede wordt de invloed van een vóór-Indo-Europese substraattaal genoemd. Ten derde zou het taalcontact tijdens de Grote Volksverhuizing een rol gespeeld kunnen hebben. Ten vierde wordt naar de rol van het Latijn en van de pan-Europese middeleeuwse cultuur verwezen. Ten slotte wordt de invloed van de gezamenlijke Europese cultuur vanaf de Renaissance als een mogelijke bron van de talige convergentie in Europa genoemd.

De twee laatste verklaringen, de invloed van de cultuur van de middeleeuwen en van de renaissance op de Europese talen, zijn inderdaad historisch, maar tegelijkertijd niet per se talig. Zulke verklaringen kunnen weliswaar ondersteunend gebruikt worden, maar kunnen niet als primaire redenen fungeren.

De laatste optie wordt door HASPELMATH (2001: 1506) zelf snel afgewezen. Zijns inziens zijn drie tot vijf eeuwen niet genoeg voor talen om de vastgestelde, gedeelde trekken te kunnen ontwikkelen. Ook als onwaarschijnlijk ziet hij het behoud van oorspronkelijke Indo-Europese kenmerken omdat de pan-Europese kenmerken nieuwere innovaties moeten zijn. Echter ook in ander opzicht is de Indo-Europese verklaring niet mogelijk. Taalbonden mogen namelijk niet uitsluitend op gene- 
tische basis opgebouwd zijn omdat daardoor de centrale factor van taalcontact overbodig wordt.

Bij de tweede verklaring, namelijk van een voor-Indo-Europese substraattaal, drukt HASPELMATH (1998: 284) eveneens zijn twijfel uit. Hij verwijst hierbij naar de zogenoemde Vasconische hypothese (VENNEMANN 1994) die stelt dat het Baskisch het laatste overblijfsel van een oude niet-Indo-Europese taalfamilie vertegenwoordigt dat in Europa vóór de aankomst van de Indo-Europeanen gesproken werd. Uiteindelijk wijst Haspelmath ook deze theorie echter af, omdat de innovaties te laat optraden om hun oorsprong in de voor-Indo-Europese tijd te zoeken.

Wat de twee overblijvende verklaringen betreft, weigert HASPELMATH (1998: 285) de invloed van het Latijn te accepteren, omdat de meeste kenmerken in het Latijn afwezig waren. Hij geeft desondanks tegelijkertijd toe dat de Latijnse prescriptieve grammaticale traditie de Europese talen sterk beïnvloedde. Dit gebeurde echter niet op structureel niveau. Als voorbeeld noemt hij de dubbele ontkenning die in een aantal Europese standaardtalen niet toegestaan is, hoewel deze structuur in sommige dialecten van de betrokken talen wel gebruikelijk is.

Als enige mogelijke verklaring rest daarom het intensieve contact tussen de Europese volkeren in de volksverhuizingstijd. Hierbij rijst de vraag waarom de talen in het Oosten, oftewel voornamelijk de Slavische talen, in vergelijking met de Romaanse en continentale Germaanse talen door hun contacten in dezelfde periode minder beïnvloed werden. Deze vraag blijft echter onbeantwoord.

Op een algemeen niveau is de poging om de twaalf Europeanismen te verklaren problematisch aangezien Haspelmath probeert voor alle kenmerken een gezamenlijke historische interpretatie te vinden. Bovendien zijn sommige van zijn verklaringen cultureel gemotiveerd, zoals de invloed van het Latijn op de Europese standaardtalen, of genetisch gemotiveerd. De bediscussieerde verklaringen zijn daarbij niet primair van belang voor de twaalf Europeanismen. Zij zijn enkel een poging om het typologisch onderzoek a posteriori historisch te onderbouwen.

\section{Conclusie}

Het onderzoek naar taalbondverschijnselen heeft in een reeks gevallen interessante resultaten opgeleverd, bijvoorbeeld in het geval van de bekende taalbond op de Balkan. Als het echter om het onderzoek naar de pan-Europese taalbond gaat, zijn de bevindingen nogal problematisch.

Hoewel het onderzoek naar Standard Average European vooral typologisch van aard is, worden de resultaten ervan als taalbondverschijnselen gepresenteerd. Om dat te rechtvaardigen worden vaak of culturele of genetische argumenten gebruikt, terwijl de historische dimensie, die voor het taalbondonderzoek essentieel zou moeten zijn, niet genoeg beklemtoond wordt. Deze methodologische gebreken zijn echter geenszins alleen voor het onderzoek naar Standard Average European typerend. Taalbonden zijn namelijk, aldus Thomason en Kaufman, in het algemeen "notoriously messy". 
Des te belangrijker is het om bij de studie naar potentiële taalbondverschijnselen de historische dimensie van het onderzoek niet te vergeten zodat de verwarring ten minste gedeeltelijk verminderd kan worden.

\section{Bibliografie}

AUER, Peter (2004): Non-Standard Evidence in Syntactic Typology - Methodological Remarks on the Use of Dialect Data vs Spoken Language Data. In: KORTMANN, Bernd: Dialectology Meets Typology: Dialect Gramar from a Cross-Linguistic Perspective. Berlin. 69-82.

AUWERA, Johan van der (2009): Deutsch als eine/die durschnittseuropäische Sprache. In: STOLZ, Christel (ed.): Unsere sprachlichen Nachbarn in Europa. Die Kontaktbeziehungen zwischen Deutsch und seinen Grenznachbarn. Bremen. 175-187.

AUWERA, Johan van der (2011): Standard Average European. In: KORTMANN, Bernd - AUWERA, Johan van der (eds.): The Languages and Linguistics of Europe: A Comprehensive Guide. Berlin. 291-306.

BECKER, Henrik (1948): Der Sprachbund. Leipzig - Berlin.

BIRNBAUM, Henrik (1965): Balkanslavisch und Südslavisch. Zur Reichweite der Balkanismen im südslavischen Sprachraum. In: Zeitschrift für Balkanologie (3). 12-63.

DAHL, Östen (1990): Standard Average European as an Exotic Language. In: BECHERT, Johannes - BERNINI, Giuliano - BURIDANT, Claude (eds.): Toward a Typology of European Languages. Berlin - New York. 3-7.

DÉCSY, Gyula (1973): Die linguistische Struktur Europas. Wiesbaden.

FRIEDMAN, Victor A. (2012): Europe, Eurasia, Southeast Europe, and Southeast Aisa: on the Question of Areal Linguistics in the $21^{\text {st }}$ Century. In: Philologica Jassyensia 1 (15). 113-124.

HAMP, Eric P. (1977): On Some Questions of Areal Linguistics. In: WHISTLER, Kenneth - VAN VALIN, Robert (eds.): Proceedings of the 3rd Annual Meeting of the Berkeley Linguistics Society, Berkeley. 279-282.

HASPELMATH, Martin (1998): How Young Is Standard Average European? In: Language Sciences 20 (3). 271-287.

HASPELMATH, Martin (2001): The European Linguistic Area: Standard Average European. In: Language Typology and Language Universals. 1492-1510.

HÜNING, Matthias (2002): Zwischen Deutsch und Englisch. Aspekte der sprachlichen Identität des Niederländischen. In: UFFELEN, Herbert van (ed.): Sprache und Identität. Akten des Symposiums zum 10-jährigen Bestehen der Nederlandistik am 18. und 19. Oktober 2002 in Wien. Wien. 143-158.

HÜNING, Matthias (2008): Hoe talen elkaar ontmoeten: over taalcontact en convergentie. In: KALLA, Irena Barbara - CZARNECKA, Bożena: Neerlandistische ontmoetingen. Trefpunt Wroctaw. Wrocław. 40-53.

JAKOBSON, Roman (1931a): Über die phonologischen Sprachbünde. In: JAKOBSON, Roman (1962): Selected Writings I: Phonological Studies. ,s-Gravenhage. 137-143.

JAKOBSON, Roman (1931b): Kharakteristike evrazijskogo jazykovogo sojuza. In: JAKOBSON, Roman (1962): Selected Writings I: Phonological Studies. ,s-Gravenhage. 143-201.

KLAGSTAD, Harold L. (1963): Toward a morpho-syntactic treatment of the Balkan linguistic group. In: American Contributions to the Fifth International Congress of Slavists: Sofia, September 1963. The Hague. 179-189. 
KÖNIG, Ekkehard (2010): Projekt EUROTYP. In: HINRICHS, Uwe (ed.): Handbuch der Eurolinguistik. Wiesbaden. 425-434.

KOPITAR, Bartholomäus (1829): Albanische, walachische u. bulgarische Sprache. In: (Wiener) Jahrbücher der Literatur 46. 59-106.

KORTMANN, Bernd (2009): Die Rolle von (Nicht-Standard-)Varietäten in der europäischen (Areal-)Typologie. In: HINRICHS, Uwe - REITER, Norbert - TORNOW, Siegfried (eds.): Eurolinguistik: Entwicklung und Perspektiven. Wiesbaden. 165-187.

LEWY, Ernst (1964): Der Bau der europäischen Sprachen. Tübingen.

LIST, Johann-Mattis (2014): Sequence Comparison in Historical Linguistics. Düsseldorf.

MASICA, Colin P. (2001): The Definition and Significance of Linguistic Areas: Methods, Pitfalls, and Possibilities (with Special Reference to the Validity of South Asia as a Linguistic Area). In: RAJENDRA, Singh (ed.): The Yearbook of South Asian Languages and Linguistics. New Delhi. 205268.

MIKLOSISCH, Franz von (1861): Die slavischen Elemente im Rumunischen. Wien.

MURELLI, Adriano - KORTMANN, Bernd (2011): Non-Standard Varieties in the Areal Typology of Europe. In: KORTMANN, Bernd - AUWERA, Johan van der (eds.): The Languages and Linguistics of Europe: A Comprehensive Guide. Berlin - New York. 525-544.

POTTELBERGE, Jeroen van (2001): Sprachbünde: Beschreiben sie Sprachen oder Linguisten? In: Linguistik Online 1 (01). 1-26.

SEILER, Guido (2011): Non-Standard Average European. Een presentatie gehouden aan de Vrije Universiteit Berlijn op 13 december 2011.

STOLZ, Thomas (2006): Europe as a Linguistic Area. In: BROWN, Keith (ed.): Encyclopedia of Language and Linguistics. Oxford. 279-295.

THOMASON, Sarah G. - KAUFMAN, Terrence (1988): Language Contact, Creolization, and Genetic Linguistics. Berkeley.

TROEBETSKOJ, Nikolaj S. (1920): Evropa i chelovechestvo [Europa en de mensheid]. Sofia.

TROEBETSKOJ, Nikolaj S. (1928): Proposition 16. In: Acte du premier congrès des linguistes à la Hague. Den Haag. 17-18.

VENNEMANN, Theo (1994): Linguistic Reconstruction in the Context of European Prehistory. In: Transactions of the Philological Society (92). 213-282.

WHORF, Benjamin L. (1941): The Relation of Habitual Thought and Behavior to Language. In: SPIER, Leslie, HALLOWELL, Alfred I., NEWMAN, Stanley S. (eds.): Language, Culture, and Personality: Essays in Memory of Edward Sapir. Menasha. 75-93.

PhDr. Martin Konvička, M.A. / martin.konvicka@fu-berlin.de

Freie Universität Berlin, Institut für Englische Philologie

Habelschwerdter Allee 45, 14195 Berlin, Germany 
